\title{
VALORACIÓN CONTABLE DE LA INVERSIÓN EXTRANJERA: EL CASO DE LA COMPAÑÍA TELEFÓNICA NACIONAL DE ESPAÑA Y LA CANTIDAD NETA INVERTIDA (1924 - 1932)
}

\author{
ACCOUNTING VALUATION OF FOREIGN INVESTMENT: THE \\ CASE OF THE NATIONAL TELEPHONE COMPANY OF SPAIN AND \\ THE NET AMOUNT INVESTED (1924-1932)
}

\author{
Casasola Balsells, M.A1. \\ Pérez Chamorro, V.A. * \\ Sánchez Barrios, $M$. \\ Gutiérrez Hidalgo, F.
}

*Autor de Contacto: vapercha@upo.es

\section{RESUMEN}

En España, ha tenido especial importancia la participación de capital extranjero en la modernización industrial a finales del siglo XIX y principios del siglo XX. Sin embargo, en este periodo la literatura en Historia de la Contabilidad ha prestado escasa atención a las prácticas contables relacionadas con la valoración de la inversión extranjera y en especial en empresas concesionarias de servicios públicos del Estado.

En consecuencia, el trabajo tiene como objeto describir las prácticas y exponer las críticas realizadas a la valoración contable de la inversión realizada por la “Compañía Telefónica Nacional de España” (CTNE), subsidiaria de norteamericana "International Telephone and Telegraph Corporation” (ITT), a efectos del rescate por el Estado y denominada "Cantidad Neta invertida”. El análisis se lleva a cabo desde el inicio de la concesión monopolista del servicio telefónico nacional otorgada durante la Dictadura de Primo de Rivera en 1924 hasta 1932 , cuando durante la Segunda República se intentó a través de un Proyecto de Ley declarar nula e ilegal la concesión y proceder a su incautación.

Los resultados del trabajo identifican las prácticas contables sobre la cantidad neta invertida llevadas a cabo por la CTNE y su divulgación en las memorias anuales. Asimismo, se exponen las principales críticas realizadas en cuanto a la valoración contable de esta partida, resaltando la insuficiente depreciación contable de las

\footnotetext{
${ }^{1}$ Los autores agracen el apoyo económico del Proyecto de Investigación de la Junta de Andalucía “Andalucía, Cruce de Culturas: una Visión desde la Contabilidad (PAIDI SEJ-4129)”.
}

DE COMPUTIS Revista Española de Historia de la Contabilidad Spanish Journal of Accounting History 
infraestructuras telefónicas, la inclusión de ciertos gastos amortizables como el impuesto del Timbre o los costes imputados a las infraestructuras en el momento de su adquisición.

\begin{abstract}
It has been particularly important the contribution of foreign investment in the industrial modernization in the late nineteenth and early twentieth century in Spain. However, in this period Accounting History literature has paid little attention to accounting practices related to the valuation of foreign investment and especially to state concessions.

Accordingly, the objective of the paper is to describe the practices and expose the criticisms of the accounting valuation of the named "net amount invested" by "National Telephone Company of Spain" (CTNE), a subsidiary of the American "International Telephone and Telegraph Corporation" (ITT). The analysis is conducted from the beginning of the state-granted monopoly provided 1924, during the dictatorship of Primo de Rivera, until 1932, when the Second Republic pushed through a bill to cancel the concession.

The results of the study identified the accounting practices of the net amount invested undertaken by the CTNE and its disclosure in the annual report. Also, the main criticisms among contemporaries are discussed, highlighting the inadequate accounting depreciation of the telephone infrastructure, the capitalization of certain tax expenses and the overvaluation of some infrastructure assets at the time of acquisition.
\end{abstract}

PALABRAS CLAVE:

Historia de la Contabilidad; Cantidad Neta Invertida; Compañía Telefónica Nacional de España; International Telephone and Telegraph Corporation; Memoria anual.

KEYWORDS:

Accounting History; Net Amount Invested; Compañía Telefónica Nacional de España; International Telephone and Telegraph Corporation; Annual Report.

\title{
1.- Introducción
}

En España, ha tenido especial importancia la participación de capital extranjero en la modernización industrial a finales del siglo XIX y principios del siglo XX (Tortella, 2008). A este respecto pueden señalarse las inversiones directas en compañías prestatarias de servicios públicos - como el suministro de agua potable, energía o transporte - donde se hacía necesaria la financiación de importantes infraestructuras (Campillo, 1963). En este periodo la literatura en Historia de la Contabilidad ha prestado escasa atención a las prácticas contables relacionadas con la valoración de la inversión directa extranjera y en especial en empresas concesionarias de servicios públicos del Estado (Hernández Esteve, 2013).

En consecuencia, el trabajo tiene como objeto describir y analizar la valoración contable de la inversión realizada por la Compañía Telefónica Nacional de España (en adelante CTNE) desde el inicio de la concesión monopolista del servicio telefónico nacional otorgada durante la Dictadura de Primo de Rivera en 1924 hasta 1932, cuando durante la Segunda República se discutió en las Cortes un Proyecto de Ley donde se declaraba ilegal y nula la adjudicación de la concesión y se procedía a su incautación por el Estado.

Durante este periodo, la CTNE estuvo gestionada por la empresa norteamericana International Telephone and Telegraph Corporation (en adelante ITT), quien tenía el control accionarial, en alianza con los grupos financieros españoles Urquijo e Hispano Americano.

DE COMPUTIS Revista Española de Historia de la Contabilidad Spanish Journal of Accounting History 
Desde los primeros años de que se otorgara la concesión a la CTNE se produjo un cambio sustancial en la modernización y expansión del sistema telefónico en España. No obstante, la gestión de la CTNE en estos años no estuvo exenta de críticas, siendo una de ellas la valoración contable de la inversión realizada por la CTNE a efectos del rescate de la concesión por el Estado denominada "cantidad neta invertida".

En el trabajo se muestra, por un lado, cómo debía ser valorada dicha cantidad neta invertida por la CTNE a partir de la información contable, así como analizar su divulgación en la memoria anual. Por otro lado, se exponen las principales críticas realizadas en la época en cuanto a la valoración contable de esta partida, y que llevaron entre otras cuestiones a la intención durante la Segunda República de incautar la concesión.

A tal efecto el manuscrito se estructura en cuatro apartados. En el apartado segundo, se realiza un breve apunte histórico de la creación de la CTNE, su control por la ITT y de la concesión realizada del servicio telefónico a la CTNE. En el tercer apartado, se expone la composición de la cantidad neta invertida según las Bases y el Reglamento de la Concesión y la información divulgada en la memoria anual. En el cuarto apartado, se exponen las críticas realizadas sobre la valoración contable de la cantidad neta invertida. En el último apartado se incluyen las conclusiones al trabajo.

\section{2.- La concesión del servicio telefónico a la CTNE (1924-1932)}

El servicio telefónico surge en España tímidamente a finales del siglo XIX. Debido a la escasa capacidad de inversión existente se implanta principalmente mediante redes urbanas en las principales ciudades españolas. A partir de las reformas llevadas a cabo en 1907 y hasta el inicio de la concesión a la CTNE en 1924 se produce un cierto desarrollo en la modernización del servicio telefónico mediante el desarrollo de un servicio interurbano pero con muchas limitaciones (Calvo, 1998; Nadal, 2007).

Otro aspecto a señalar es que en este periodo no había un criterio único sobre la explotación del servicio telefónico, coexistiendo un modelo de explotación privada y pública con diferentes intereses. El caos telefónico que había en España, caracterizado por muchas concesiones y sistemas, en muchos casos sin posibilidad de conexión entre unos y otros, unido a la necesidad de atraer capital extranjero que permitiera un mayor desarrollo y modernización del servicio, llevó finalmente a que el Estado otorgara el monopolio a la CTNE, la cual contaba con el respaldo tecnológico y financiero de la empresa americana ITT.

El mosaico de concesiones existentes, según recoge Cabezas (1974) era el siguiente: de los 78.124 teléfonos instalados, el Estado explotaba, el 28\%; las corporaciones locales, un 9\%; empresas privadas concesionarias importantes, entre las que figuraban la Compañía Peninsular de Teléfonos, el 33\%. El otro 30\% lo explotaban pequeños concesionarios particulares. Se debe añadir que la tecnología telefónica, vigente en este período, era suministrada por filiales de dos prestigiosas multinacionales: Siemens y Ericsson.

En estos modelos de explotación del servicio telefónico subyacían distintos intereses de gestión pública y privada. En primer lugar; el Cuerpo de Telégrafos que argumentaba que el servicio telefónico debía de ser prestado por el Estado, directamente, en régimen de monopolio, como en otros países, de la misma forma que otros servicios como el correo y la telegrafía. En segundo lugar; Instituciones públicas regionales, caso de la Diputación de Guipúzcoa y la Mancomunidad de Cataluña, defendían la desconcentración territorial del servicio; en tercer lugar, los concesionarios privados, los cuales se regían por los criterios de rentabilidad

DE COMPUTIS Revista Española de Historia de la Contabilidad Spanish Journal of Accounting History 
económica al margen de la rentabilidad social, instalando sus activos en las zonas de más población y con más niveles de renta. Estos criterios siguieron latentes durante muchos años, y fueron defendidos arduamente de distintas formas frente a los protagonistas del nacimiento de la CTNE, a través de la prensa, a nivel político e incluso a nivel parlamentario.

Esta situación desembocó a que el Rey Alfonso XIII, a propuesta del General Primo de Rivera, presidente del Directorio Militar, firmara el 25 de agosto de 1924, en Santander, un Real Decreto (Gaceta, número 241, de 28 de agosto de 1924) por el que se concedía a la CTNE, empresa de reciente creación, la explotación del monopolio del servicio telefónico en España durante veinte años. Cuatro días más tarde se firma un contrato privado entre la CTNE y la ITT por la cual ésta tomaba el control efectivo de la gestión y se convertía en asesor y suministrador exclusivo (Carballo, 1979; Pérez Yuste, 2004).

Inicialmente, el capital social de la CTNE fue de un millón de pesetas, distribuido en dos mil acciones de quinientas pesetas cada una, todas ellas fueron suscritas. Los Estatutos de la Compañía establecieron llevar a cabo ampliaciones de capital hasta llegar a un capital social de trescientos millones de pesetas, de las cuales cien millones eran ordinarias, en poder de la ITT, y doscientos millones en acciones preferentes, para otros accionistas.

El poder efectivo de la Compañía, estaba en los propietarios de las acciones ordinarias, en este sentido se puede contrastar en las cuentas anuales de la Compañía la gran desproporción entre las acciones ordinarias y preferentes, estas últimas ni siquiera tenían derecho de voto, tan sólo en lo preceptuado en el antiguo Código de Comercio en su artículo 168, en lo que pudiera afectar a las modificaciones de los Estatutos o modificaciones en el capital social, que se contempla en el artículo 21 de los mismos. Para que ese privilegio que tenía la ITT siguiera latente, se modificó en asamblea extraordinaria el artículo 21 de los Estatutos de la Compañía, el nuevo texto de tal manera que para la validez de los acuerdos a que se refería el artículo 168 del Código de Comercio, fuera necesario adoptarlos por mayoría absoluta de cada clase de acciones, este fue el mecanismo legal que utilizó la ITT para tener el poder de la Compañía (Pérez Yuste, 2004).

La remuneración de las acciones preferentes se fijó en el 7\% anual acumulativo sobre beneficios, mientras que para las acciones ordinarias se determinaba por el dividendo acordado cada año (art.8 de los Estatutos). Además, en otro orden de cosas, la retribución de los administradores estaba contemplada en el artículo 27; entre las funciones del Consejo de Administración estaba la remuneración de los altos funcionarios. En el artículo 31 aparecen todas las funciones que tiene el Consejo de Administración, entre ellas: acordar tarifas de los servicios, aprobar la plantilla del personal y fijar sus sueldos, celebrar contrato de cualquier naturaleza, nombramientos de apoderados, contables, asesores, acordar y realizar operaciones de crédito, así como emisión, conversión, amortización, reembolso y compraventa a cuenta de la Compañía de obligaciones, cédulas, y otros. El artículo 32 hace referencia a la creación de un Comité Ejecutivo para aliviar las tareas del Consejo y dar más celeridad a los temas relevantes.

La decisión de otorgar el monopolio en última instancia a la empresa americana ITT, ignoró otras propuestas realizadas por tres empresas multinacionales del sector como la Compañía Española de Teléfonos Ericcson, de origen sueco, la New Antwerp Telephone and Electric Works, de origen belga y la alemana Siemens \& Halske (Pérez Yuste, 2004). Asimismo esta decisión creó también un cierto malestar de la Dirección General de Telégrafos ante la Jefatura del Gobierno por la falta de consideración de las propuestas realizadas, así como de los concesionarios de la explotación del servicio telefónico.

DE COMPUTIS

\section{Revista Española de Historia de la Contabilidad Spanish Journal of Accounting History}


La forma de adjudicación del monopolio fue polémico y objeto de críticas posteriores al realizarse de una forma arbitraria y obviando el procedimiento de subasta o concurso que establecía la Ley de Administración y Contabilidad de 1911. Otro aspecto criticado en la adjudicación fue la pérdida de soberanía del Estado, al conceder a las bases que regulaba la concesión del Contrato entre la CTNE y el Estado una posición legal superior al marco jurídico administrativo vigente. En el Real Decreto se incluía explícitamente en el art. 2 que prevalecía lo dispuesto en las bases del Contrato en caso de conflicto con cualquier disposición legal. De esta forma se otorgaba a la CTNE una libertad de actuación en muchos ámbitos quedando las facultades de control por el Estado de la explotación del servicio limitadas. Asimismo el carácter de empresa extranjera de la ITT acentuaba esta pérdida de soberanía.

El contrato entre la CTNE y el Estado se acompaña de veintiséis bases que regulan la explotación del monopolio. En las mismas se especifican un conjunto de actuaciones a realizar por todo el territorio español en aras a la modernización de las redes urbanas e interurbanas existentes. Asimismo se otorgaba a la compañía las infraestructuras y redes de titularidad estatal así como permitía la potestad reglamentaria a la CTNE de valorar y expropiar a los concesionarios sus redes e instalaciones. Con respecto a la llevanza de la contabilidad, se da libertad a la empresa al indicar únicamente en la base vigésimo cuarta que deberá llevar a cabo la misma siguiendo "las prácticas contables más adelantadas".

El Estado con el objeto de promover una mayor inversión en el sistema telefónico, abaratar las tarifas y aumentar la recaudación a través de la participación en los beneficios suprime en el Contrato con la CTNE la reversión gratuita existente a la finalización de los contratos de los concesionarios, calificándose este aspecto en la exposición de motivos incluso de "error fundamental". El razonamiento subyacente de esta idea es que al obligar a las empresas concesionarias a amortizar la inversión en el periodo concesional se limitaba la incorporación de innovaciones tecnológicas y por lo tanto se veía perjudicado el servicio prestado (Pérez Yuste, 2004).

La participación del Estado en los beneficios de la Compañía se recoge en la base séptima y consta de tres apartados. En el primero se fijaba el canon del $10 \%$ sobre los beneficios netos, que serían como mínimo del 4\% de los ingresos brutos de explotación. En el segundo se estipula una participación adicional en los beneficios netos. Y en el tercero se indica que la cantidad mínima que va a recibir es la obtenida por medio de los cánones pagados por los anteriores concesionarios del servicio telefónico en el año fiscal finalizado a 31 de marzo de 1924.

Siguiendo con las bases del contrato, la referencia a la reversión no gratuita se encuentra en las bases 23, 24 y 25. La primera de ellas exponía que la Compañía en su totalidad podría ser incautada tras el periodo concesional, 20 años a cambio el Estado se comprometía a pagar la "cantidad neta invertida" que tendrá que ser demostrada en los documentos y contabilidad. Además de un premio por compensación del 15\% de la cantidad neta invertida, sin embargo, este premio disminuirá en un $1 \%$ año tras año sin que el Estado haya procedido al rescate de la Compañía, significando que después de los primeros treinta y cinco años de concesión, el Estado sólo estará obligado a pagar la cantidad neta invertida hasta ese momento, sin premio de compensación. Por otra parte, la base veinticinco establece que el Estado podrá incautar a la Compañía antes de finalizar el período de concesión, si ha cumplido de forma reiterada y manifiesta las obligaciones estipuladas en las bases del contrato. A cambio, el Estado se comprometía a pagar la cantidad neta invertida con una penalización económica que

DE COMPUTIS Revista Española de Historia de la Contabilidad Spanish Journal of Accounting History 
se encuentra entre una cantidad mínima que es del $10 \%$ de la cantidad neta invertida y un máximo de dos millones y medio de pesetas.

Otras bases importantes del contrato son las referidas a la número 24, la cual expone la definición y los componentes de tres conceptos contables claves: beneficios netos, ingresos brutos de explotación y cantidad neta invertida, además, hay que tener en cuenta que las cuotas y tarifas de servicios se calculaban atendiendo a la cantidad neta invertida, según la base vigésima. La Compañía se comprometía a presentar anualmente las cifras de resultados de la cantidad neta invertida, de acuerdo con la base vigésimo tercera junto a los balances y liquidaciones a la Delegación Oficial del Gobierno. En la base vigésimo primera se establece el plazo de presentación de los documentos contables referidos anteriormente, el cual no debería ser superior a tres meses después de la terminación del ejercicio económico. Además, explica que se considera que las cuentas están aprobadas de manera expresa, si al menos dos miembros de la Delegación dan su visto bueno; o de forma tácita, si han pasado treinta días y no ha sido notificada la resolución.

Después de la experiencia de los primeros años de vida de la CTNE, nace el Reglamento de 1929 para la ejecución del contrato de la Compañía con el Estado, el mismo se justificaba por la conveniencia de perfilar algunos detalles no recogidos en los derechos y obligaciones del Estado y de la Compañía incluidas en las bases del Contrato. Uno de los aspectos que se incorporan hace referencia al importe mínimo a reconocer anualmente a partir de 1930 como dotación de la depreciación de los activos y gastos amortizables integrantes de la cantidad neta invertida.

Los años de la dictadura de Primo de Rivera fueron de una gran actividad para Telefónica, con importantísimas realizaciones y buenos resultados económicos. En el periodo analizado se produjo el mayor esfuerzo inversor por la CTNE en aras a mejorar la calidad del sistema telefónico, entre las que pueden mencionarse la extensión del servicio automático o la modernización de los conductores (Calvo, 1996; Herranz, 2004). El nacimiento de la República, tras las elecciones del 14 de abril de 1931, y el abandono de España del Rey Alfonso XIII, supuso una mirada de análisis al septenio dictatorial pasado. El contrato de explotación del servicio telefónica entre el Estado y la Compañía no pasó desapercibido. Para dejar sin efecto el anterior contrato, el presidente del primer Gobierno de la República ordenó al ministro de Comunicaciones "un proyecto de ley, declarando ilegal la adjudicación de la reforma, reorganización y ampliación del Servicio Telefónico Nacional de 25 de agosto de 1924” (CTNE, 1933).

El tema de la legalidad o ilegalidad de la concesión y la pérdida de soberanía trajo consigo una gran polémica y grave crisis institucional a nivel nacional e internacional, que repercutió en la prensa durante algunas semanas, que se hizo más notable al saberse del envío de algunos escritos de la Embajada de los Estados Unidos al Gobierno español (Little, 1979). Finalmente, tras presentar la CTNE unas alegaciones al Proyecto de Ley (CTNE, 1933), las Cortes no aprobaron el mencionado proyecto de ley, y sí una propuesta de Manuel Azaña en el sentido de que "no ha lugar a deliberar" el asunto de la concesión del servicio telefónico (Martínez Ovejero, 2004).

A lo largo de este apartado emergen varios aspectos: en primer lugar; el nacimiento polémico y conflictivo de la Compañía, debido a la gran cantidad de concesionarios con distintos intereses, distinta calidad de servicios y distintos modelos de gestión. En segundo lugar, criticas en la elección de la Compañía proveedora de capital financiero y tecnológico, ITT, y la arbitrariedad en los mecanismos de elección. En tercer lugar; la ITT gestionó la

DE COMPUTIS

No. 19

\section{Revista Española de Historia de la Contabilidad Spanish Journal of Accounting History}


compañía de manera unilateral, dado que los derechos de votos procedentes las acciones ordinarias estaban en su poder. En cuarto lugar, la disputa entre los intereses de la ITT y el Gobierno durante la Segunda República por el rescate de la concesión.

En el siguiente apartado se trata de la importancia del documento contable: la cantidad neta invertida, su composición, su valoración. Este documento ha sido objeto de polémicas, de discusión, de conflicto entre la ITT y el Estado.

\section{3. - La cantidad neta invertida}

\subsection{La valoración contable de la Cantidad Neta Invertida}

Según la base vigésimo tercera del Contrato, transcurridos veinte años desde el inicio del Contrato entre el Estado y la CTNE - el 29 de agosto de 1944 - , y tras realizar una notificación previa con dos años de antelación, el Estado podía incautar la totalidad de instalaciones y demás elementos materiales e intangibles en poder de la CTNE para el desarrollo de su actividad. La incautación estaría condicionada a que el Estado reembolsara a la compañía la “cantidad neta invertida”, más un 15\% de esta cantidad en concepto de compensación. Esta compensación se reduce en un 1\% cada año que pase sin que el Estado ejercite este derecho.

La valoración de la cantidad neta invertida se recoge explícitamente en la base vigésimo cuarta del Contrato con el Estado, junto con otros conceptos contables como el "beneficio neto" y "los ingresos brutos de explotación”, de la siguiente forma:

“c) Cantidad Neta Invertida. - La frase “Cantidad Neta Invertida” se entenderá que comprende:

$1^{\circ}$ el pago de la cantidad que asciende la valoración especificada en la base $3^{a}$ del Contrato.

$2^{\circ}$ Todas la cantidades que la compañía haya pagado directamente a los concesionarios, de acuerdo con la base $4^{a}$ de este Contrato.

$3^{\circ}$ Todas las cantidades que haya depositado la Compañía en la Caja general de Depósitos para las cuentas de los concesionarios, según lo previsto en la base $5^{a}$ de este Contrato.

$4^{\circ}$ Las sumas, además de las antedichas, que la compañía haya gastado en la construcción, renovación, mejoras o adquisición de las instalaciones y propiedades, de las que el Estado pueda incautase con arreglo a lo previsto en la base 23 de este Contrato.

$5^{\circ}$ El gasto total que represente a la Compañía la obtención de fondos para atender a las instalaciones y adquirir las propiedades, de las que el Estado puede incautarse según la base 23 de este Contrato, incluyendo en dichos gastos los descuentos de las operaciones financieras de la Compañía.

Del total que resulte de las cinco precedentes partidas, será deducido:

$6^{\circ}$ El total de las sumas que hayan sido llevadas a la cuenta de depreciación de las instalaciones y propiedades, de las que el Estado puede incautarse según la base 23 de este Contrato.

DE COMPUTIS Revista Española de Historia de la Contabilidad Spanish Journal of Accounting History 
$7^{\circ}$ El total de sumas destinadas a amortizar el gasto total para la obtención de los fondos mencionados en la sección c) $5^{\circ}$ de esta base.

$8^{\circ}$ El producto líquido de la venta de cualquier propiedad, cuyo coste hubiera sido previamente incluido en las partidas c) de esta base."

Fuente: Base 24 del Contrato entre el Estado Español y la Compañía Telefónica Nacional de España.

Por lo tanto, la valoración inicial de la inversión realizada por la CTNE comprende tres aspectos:

En primer lugar, el valor de adquisición de todas las instalaciones y propiedades transferidas por el Estado (punto $1^{\circ}$ ) o mediante acuerdo directo con concesionarios (punto $2^{\circ}$ ). Asimismo, incluye los depósitos realizados por la CTNE por las cantidades convenidas con los concesionarios vendedores o derivados de una valoración realizada por el Estado cuando la CTNE no haya llegado a un acuerdo con los mismos (punto $3^{\circ}$ ).

En segundo lugar, se incluyen los importes relativos a la modificación o habilitación de las instalaciones adquiridas a concesionarios o transferidas por el Estado para adecuarlas a las actividades de explotación de la CTNE. Asimismo los importes relacionados con la construcción, renovación y mejora de las mismas (punto $4^{\circ}$ ).

$\mathrm{Y}$ en tercer lugar, los gastos financieros - principalmente derivados de la suscripción de acciones ordinarias y preferentes y emisión de obligaciones por la CTNE - necesarios para adquirir y atender las instalaciones, incluyendo los descuentos concedidos en las operaciones financieras (punto $5^{\circ}$ ).

Al total de esta valoración inicial deben deducirse para obtenerse el valor neto de la cantidad invertida las siguientes tres partidas: En primer lugar, las depreciaciones realizadas a las instalaciones y propiedades que el Estado puede incautarse (punto $6^{\circ}$ ). El artículo 83 del Reglamento de 1929 amplia el contenido de este apartado indicando las siguientes reglas para determinar el valor global de la depreciación a reconocer anualmente a partir de 1930:

"La suma total que se fije por depreciación y amortización en 1930, incluyendo útiles, enseres y descuento de emisiones, será por lo menos, el 1,50 por 100 de la cantidad neta invertida en 31 de diciembre de 1929. El referido mínimo de 1,50 por 100 regirá durante los años 1930 a 1933 inclusive, y aumentará en los años sucesivos hasta 1944, siempre con el mínimo a razón de 0,125 por año de la cantidad neta invertida a fin del año anterior.

Si en algún año se adoptaran para la depreciación y amortización total cifras superiores al mínimo que corresponda, según lo convenido en el apartado precedente, al año siguiente no podrá aquélla ser menor, a no ser que disminuyan las utilidades de la compañía”.

Fuente: Art. 83 del Reglamento para la ejecución del contrato celebrado entre el Estado y la Compañía Telefónica Nacional de España.

En segundo lugar, los importes relativos a la amortización de los gastos originados en la obtención de fondos necesarios para adquirir y atender las instalaciones (punto $7^{\circ}$ ). Y por

DE COMPUTIS Revista Española de Historia de la Contabilidad Spanish Journal of Accounting History 
último, el producto líquido de la venta de todas instalaciones y propiedades incluidas en la valoración inicial de la cantidad invertida.

Otra característica fundamental de la regulación contractual entre el Estado y la CTNE sobre la valoración del reembolso de la cantidad neta invertida es que "será hecho en oro por el total de esta cantidad [neta invertida] calculada en oro, o, su equivalente, en moneda española de curso legal" (base vigésimo tercera del Contrato; CTNE, 1930, p.56). Igualmente, el importe relativo a la compensación será reembolsado en la misma forma que para la cantidad neta invertida.

En el contrato se pactó valorar la inversión realizada en una moneda estable durante la concesión con el objeto de evitar que el riesgo de una depreciación de las pesetas corrientes en el reembolso de la cantidad neta invertida perjudicara a la Compañía.

De esta forma lo justificaba la Compañía en las alegaciones presentadas al Proyecto de Ley de Martínez Barrios:

En cuanto al abono en oro de la Cantidad Neta Invertida, debe considerarse que el más elemental deber de prudencia y de equidad obligaba a la Empresa y al Estado a referir sus inversiones a una moneda estable. Lo contrario hubiera sido llevar al capital a un negocio de franca especulación y al fracaso seguro de la Compañía, a la que no hubiera acudido el capital al no verse garantizado.

Fuente: CTNE (1933, p.168)

La valoración del reembolso de la Cantidad Neta Invertida en pesetas de curso legal a efectuar en el momento del reembolso se realizaría utilizando la "peseta oro" correspondiente a los seis meses anteriores a la entrega de las propiedades al Estado:

"Para calcular la cantidad en moneda española de curso legal será convertida en esta moneda, según el promedio del valor de la peseta oro con respecto a la moneda española de curso legal, correspondiente a los seis meses anteriores a la fecha de entrega de las propiedades da la Compañía.

Fuente: Base vigésimo tercera del Contrato (CTNE, 1930, p.56)

Además, para evitar un tipo de cambio desfavorable para la Compañía en los seis meses anteriores al reembolso debía de ir valorándose la Cantidad Neta Invertida mensualmente en pesetas oro según el tipo de cambio oficial publicado por la Hacienda.

"Tal cantidad neta invertida, cifrada mensualmente en moneda española de curso legal, será convertida en su valor en oro, según el promedio correspondiente al mes respectivo, del valor de la moneda española de curso legal con respecto a dicha «peseta oro». Para los cálculos se tomará como base la «peseta oro», representada por la cantidad fija de 322,5804 miligramos oro de una ley de 900 milésimas, o sea la vigésima quinta parte de la moneda oro llamada «Alfonso» 0 «centén» de 25 de pesetas, (...)”

Fuente: Base vigésimo tercera del Contrato (CTNE, 1930, p.56)

DE COMPUTIS Revista Española de Historia de la Contabilidad Spanish Journal of Accounting History 
De esta forma quedaría fijada mensualmente la valoración de la inversión realizada en pesetas oro y la Compañía evitaría quedar perjudicada por un tipo de cambio desfavorable en pesetas corrientes. En las alegaciones efectuadas al Proyecto de Ley de Martínez Barrios por la Compañía se justificaba la necesidad de proceder a la conversión en pesetas oro durante el transcurso del Contrato de la siguiente forma:

Repetimos que el sistema de cifrar la Cantidad Neta Invertida, lo estimamos lógico y equitativo, pues si, por ejemplo, grandes inversiones fueren hechas en épocas de cambios muy bajos de la peseta, o sea con equivalentes en oro pequeños, y en el momento de la incautación el promedio del valor oro de la peseta moneda legal, es alto durante los seis meses precedentes a la incautación, podrá ocurrir que el equivalente en pesetas moneda legal a la Cantidad Neta Invertida en oro, sea inferior a la suma de las pesetas moneda legal invertida durante el transcurso del Contrato.

Fuente: CTNE (1933, p.169)

Una restricción que incluye en el contrato con relación al reembolso en oro es que "esta equivalencia no será menor que el total de la cantidad neta invertida en moneda española de curso legal [...], en el caso único de que esté en España el setenta y cinco por ciento, por lo menos, del total del Capital de la Compañía” (base vigésimo tercera del Contrato, CTNE, 1930, p.56).

Como los cálculos de la cantidad neta invertida se realizaban por la CTNE con la información de los libros de Contabilidad, la base vigésimo tercera recoge la obligatoriedad de incluir al final de cada ejercicio económico dicha valoración, así como su conversión mensual en pesetas oro, en las cuentas anuales. Esta información debía de ser sometida a aprobación, junto con el Balance de Situación y la Cuenta de Pérdidas y Ganancias, por los delegados del Gobierno en la CTNE en un plazo no superior a tres meses después de la terminación del ejercicio económico.

No obstante, no es necesario más que la mayoría de los delegados para su aprobación, los cuales no tienen derecho a veto. Cabe decir además que este derecho no se regula en el Reglamento de 1929, en contradicción con el art. 1 del Real Decreto Ley de 29 de diciembre de 1928, relativo a la intervención del Estado en compañías y empresa concesionarias (Carballo, 1979). El informe emitido por la delegación del gobierno a este respecto debía incluirse en la memoria anual de la Compañía (véase ejemplo en figura 1).

DE COMPUTIS Revista Española de Historia de la Contabilidad Spanish Journal of Accounting History 
Figura 1. Informe de la delegación oficial del gobierno en la CTNE.

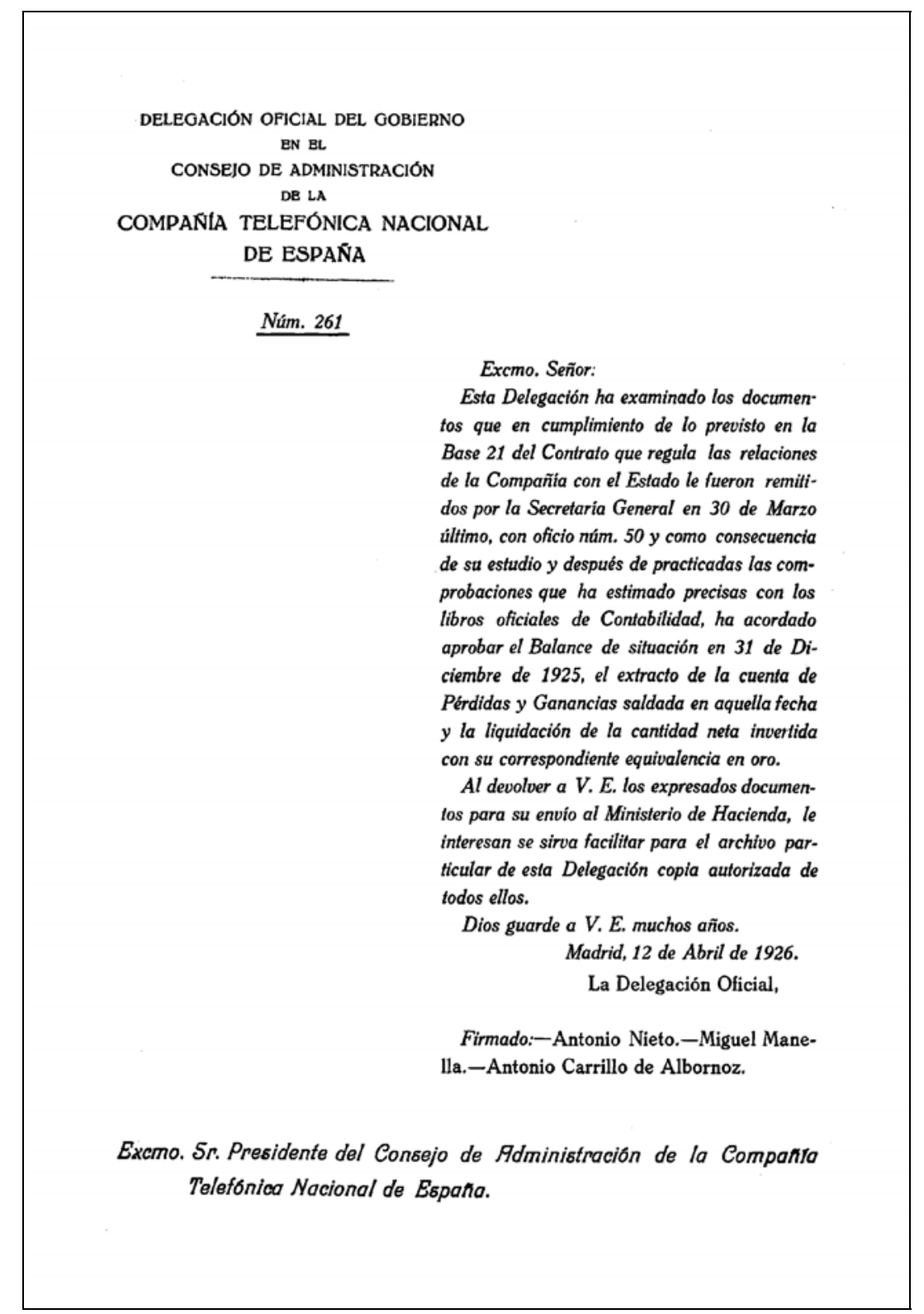

Fuente: Memoria anual CTNE (1925; p.15)

Por otra parte, además de constituir el importe a reembolsar al final de la concesión, el valor de la cantidad neta invertida tenía un efecto directo en el cálculo de las tarifas que debían de pagar los abonados y en los ingresos a percibir por el Estado durante la concesión.

Según la base séptima y vigésima, los ingresos producidos por las tarifas de toda clase de servicios deben ser suficientes para que los ingresos anuales netos de la CTNE permitan obtener un rendimiento anual del $8 \%$ sobre la cantidad neta invertida, más un $2 \%$ de dicha cantidad neta invertida para nutrir un fondo de reserva que alcance como máximo de un $20 \%$ sobre la cantidad neta invertida. 
Con respecto a los ingresos, la base séptima recoge la posibilidad de participar en los beneficios netos de la compañía, además del canon del 10\% de los beneficios netos a percibir anualmente por el Estado. Si los ingresos producidos por las tarifas menos los gastos relacionados con las operaciones son superiores al $8 \%$ de la cantidad neta invertida y de la dotación anual por el $2 \%$ al fondo de reserva se distribuirá la diferencia a partes iguales entre la CTNE y el Estado. Igualmente, si se cubre con los ingresos netos efectivos el 8\% de la cantidad neta invertida y el fondo de reserva alcanzan el $20 \%$ de la cantidad neta invertida.

\subsection{La Información sobre la cantidad neta invertida en las cuentas anuales de CTNE.}

\subsubsection{Información sobre la composición de la cantidad neta invertida}

Siguiendo la norma vigésimo cuarta del contrato, la CTNE incluye en la memoria anual un estado donde se detalla la composición y valor de la cantidad neta invertida en el ejercicio.

La primera memoria anual de la CTNE donde se incluye información sobre la cantidad neta invertida es la del ejercicio 1925, siendo el desglose de las partidas que componen la cantidad neta invertida el mismo con el que se formula el balance de la compañía (véase figura 2).

Figura 2: Divulgación de la composición de la CNI en la memoria anual

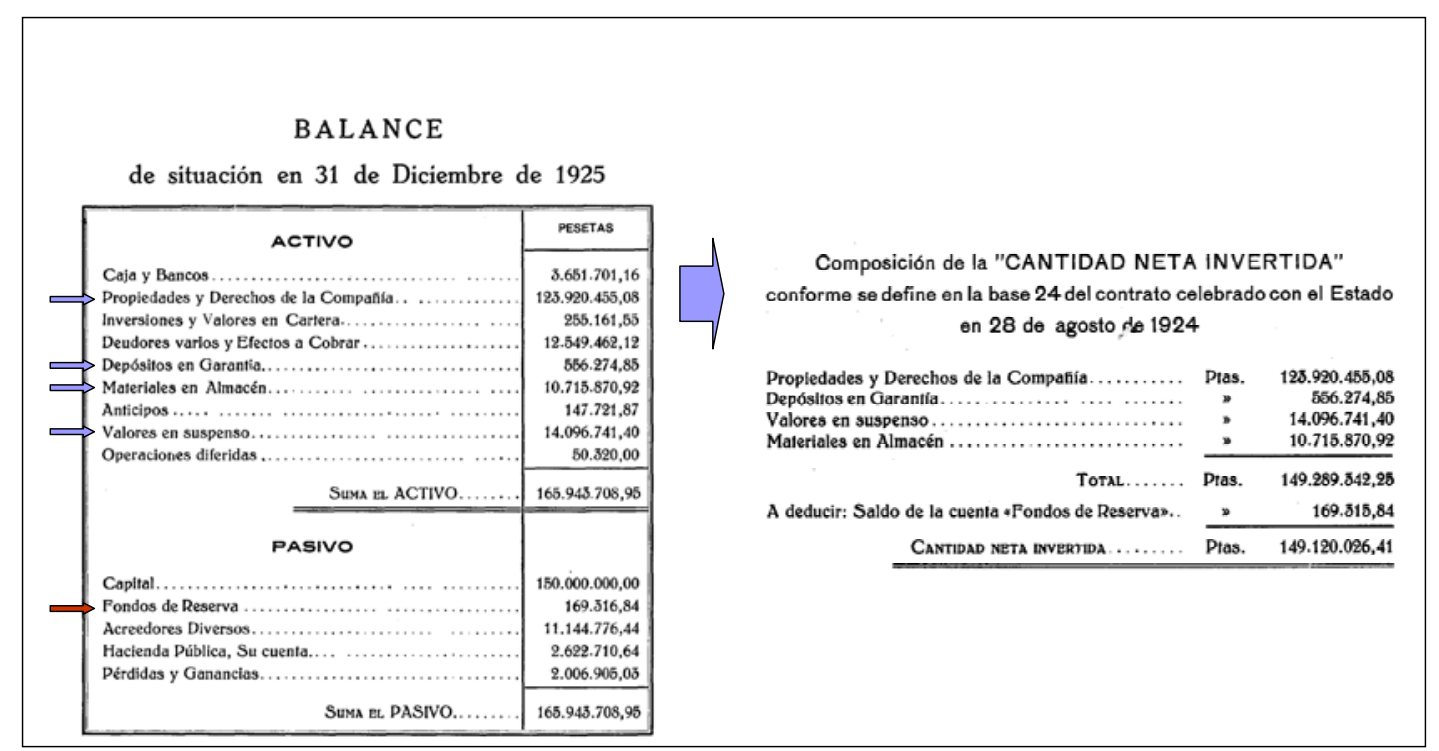

Fuente: Elaboración propia a partir de la Memoria anual CTNE 1925; p.10 y 13

Esta característica se mantiene en la información proporcionada en las memorias anuales de los siguientes ejercicios (véase tabla 1).

$$
\text { --- insertar tabla } 1 \text { aquí --- }
$$

DE COMPUTIS Revista Española de Historia de la Contabilidad Spanish Journal of Accounting History 
En el ejercicio de 1925 se calcula a través de la agregación de cinco partidas, siendo la principal la relativa a las "propiedades y derechos de la compañía”, que según la memoria está compuesta por "gastos de constitución, equipos de centrales y aparatos telefónicos, equipos para los talleres y almacenes, líneas urbanas e interurbanas, herramientas, obras en construcción y solares y edificios” (Memoria CTNE, 1925; p.7).

Con respecto al valor de las propiedades y derechos de la compañía resalta, de los datos mostrados en el cálculo de la cantidad neta invertida, el notable incremento producido en la inversión realizada en esta materia en los primeros años de la actividad. Esta es la partida que la empresa incluye en la memoria mayor información. Suele hacerse referencia a las principales actuaciones llevadas a cabo en cuanto a adquisiciones realizadas, puesta en funcionamiento de nuevas instalaciones y modernización de la infraestructura telefónica en el ejercicio. Asimismo la memoria anual incluye un apéndice donde para las distintas poblaciones se detalla a través de tablas toda esta información.

Otra partida relacionada con las propiedades y derechos de la compañía son los “depósitos en garantía”, que se corresponden con los importes convenidos con los concesionarios vendedores o valorados por el Estado cuando no haya acuerdo. Solamente se indican importes en las memorias de 1926 y 1927. Aunque se indica en la memoria información en estos años sobre adquisiciones de concesionarios existentes en diversas localidades españolas, no se relacionan con los valores de los depósitos realizados.

Otra partida serían los “materiales de almacén” que se corresponderían con aquellos materiales y enseres no utilizados en las instalaciones y almacenados por la compañía. Al contrario que las propiedades y derechos de la compañía, durante el periodo de estudio disminuye su importe desde 30.655.390,74 pesetas en 1926 hasta 9.330.729,78 pesetas en 1931 . En la memoria no se incluye detalle de la composición de esta partida o sus variaciones durante el periodo analizado.

Los "valores en suspenso" incluidos en el cálculo de la cantidad neta invertida expresan gastos a distribuir en varios ejercicios y según la memoria se derivan de las operaciones financieras realizadas en la constitución de la sociedad y de la emisión de títulos posteriores.

A la suma de estas cuatro partidas - 149.289.342,25 ptas - se detrae en el ejercicio de 1925 la partida "fondo de reserva" - 169.315,84 ptas -, alcanzando la cantidad neta invertida un total de 149.120.026,41 pesetas. Para la partida fondo de reserva tampoco se desglosa o comenta en la memoria el valor de la misma.

Además, sorprendentemente, no se incluye en este estado el valor de la depreciación acumulada de las redes - 850.000 ptas - ni la amortización de los descuentos en la emisión de acciones - 150.000 ptas. No obstante, la compañía considera en la memoria que ambos importes son "deducibles de la cantidad neta invertida, según la base 24 del contrato con el Estado, con un importe en junto de 1.000.000,00 pesetas.” (Memoria Anual, 1925; 8). En la cuenta de pérdidas y ganancias del ejercicio 1925 se observa que estos importes no han sido considerados como parte de los gastos de explotación sino como una aplicación del beneficio, el cual el Consejo acuerda proponer a la Junta general para su aprobación.

Como se observa en la tabla 1, a partir de la memoria de 1926 se incluyen dos nuevas partidas en la composición de la cantidad neta invertida: "gastos amortizables” y "reservas y

DE COMPUTIS

No. 19
Revista Española de Historia de la Contabilidad Spanish Journal of Accounting History 
amortizaciones", sustituyendo a las partidas "valores en suspenso" y "fondo de reserva" respectivamente.

Durante el periodo analizado el valor de los gastos amortizables se incrementa hasta alcanzar casi los cuarenta y dos millones de pesetas en 1931, debido a las sucesivas ampliaciones de capital ordinario y preferente así como de obligaciones que se realizaron en los primeros años de actividad.

Con respecto a la partida "Reservas y Amortizaciones" se hace referencia en la memoria al saldo y cargo anual, desglosándose únicamente los importes dotados en el ejercicio sobre depreciación de los equipos y propiedades y sobre amortización de gastos amortizables en el debe de la cuenta de pérdidas y ganancias (véase resumen en tabla 2).

$$
\text { --- insertar tabla } 2 \text { aquí --- }
$$

De los datos mostrados en la tabla cabe señalar que, en cumplimiento con el mínimo dispuesto en el art. 83 del Reglamento, el aumento del fondo en 1930 y 1931 supone efectivamente un 1,5\% sobre la cantidad neta invertida en el ejercicio anterior. Si se calcula el porcentaje acumulado de las reservas y amortizaciones reconocidas en el periodo analizado con respecto a la inversión bruta total se aprecia que en 1932 alcanza el 5,78\%.

Asimismo se ha calculado el peso de las depreciaciones reconocidas anualmente en redes e instalaciones y de la amortización de gastos amortizables en la dotación anual por reservas y amortizaciones. En 1932 supone la depreciación anual de redes e instalaciones un 64,85\% del total, mientras para amortización de gastos amortizables un 14,08\%. A este respecto se observa cómo va cobrando mayor importancia en este periodo el valor de la depreciación de las redes y los gastos amortizables en la dotación anual de reservas y amortizaciones, ya que en 1926 suponían solamente un 20,6\% y un 3,64\% respectivamente.

En la memoria de 1929 se señala otro cambio que incide en la determinación de las "reservas y amortizaciones" y en la partida "gastos amortizables". Los importes reconocidos por el impuesto del Timbre venían incluyéndose en los gastos amortizables sobre emisión de acciones y ampliaciones de capital y su amortización en las "Reservas y amortizaciones". Debido a un requerimiento de la Delegación del Gobierno en el consejo de administración de la compañía, a partir de este ejercicio, el impuesto del Timbre se elimina de la partida "Gastos Amortizables" traspasándose a la partida "Operaciones Diferidas”. Por lo tanto, los importes amortizados dejan de formar parte de "Reservas y Amortizaciones", reduciéndose directamente en "Operaciones Diferidas”. Esta última partida no se incluye en el cálculo de la cantidad neta invertida.

Por último cabría señalar una limitación a la información mostrada sobre la cantidad neta invertida. En la información proporcionada en la memoria anual no se desglosan tres aspectos señalados expresamente en el Contrato y en el Reglamento: a) los importes relativos a la modificación o habilitación de las instalaciones adquiridas a concesionarios o transferidas por el Estado para adecuarlas a las actividades de explotación de la CTNE; b) los importes relacionados con la construcción, renovación y mejora de las instalaciones; y c) los importes obtenidos por la venta de instalaciones. Tampoco se muestra en la memoria anual las distintas partidas que forma el saldo acumulado de reservas y amortizaciones con el objeto de conocer el

DE COMPUTIS Revista Española de Historia de la Contabilidad Spanish Journal of Accounting History 
valor acumulado de la amortización de las propiedades y derechos de la compañía y de los gastos amortizables.

\subsubsection{Conversión de la cantidad neta invertida en pesetas-oro}

En la memoria anual se incluye a continuación de la información sobre la composición de la cantidad neta invertida comentada en el apartado anterior, la equivalencia mensual de la cantidad neta invertida en pesetas-oro utilizando para ello el tipo de cambio medio oficial (véase ejemplo en la figura 3).

Figura 3: Equivalencia mensual en pesetas-oro de la cantidad neta invertida

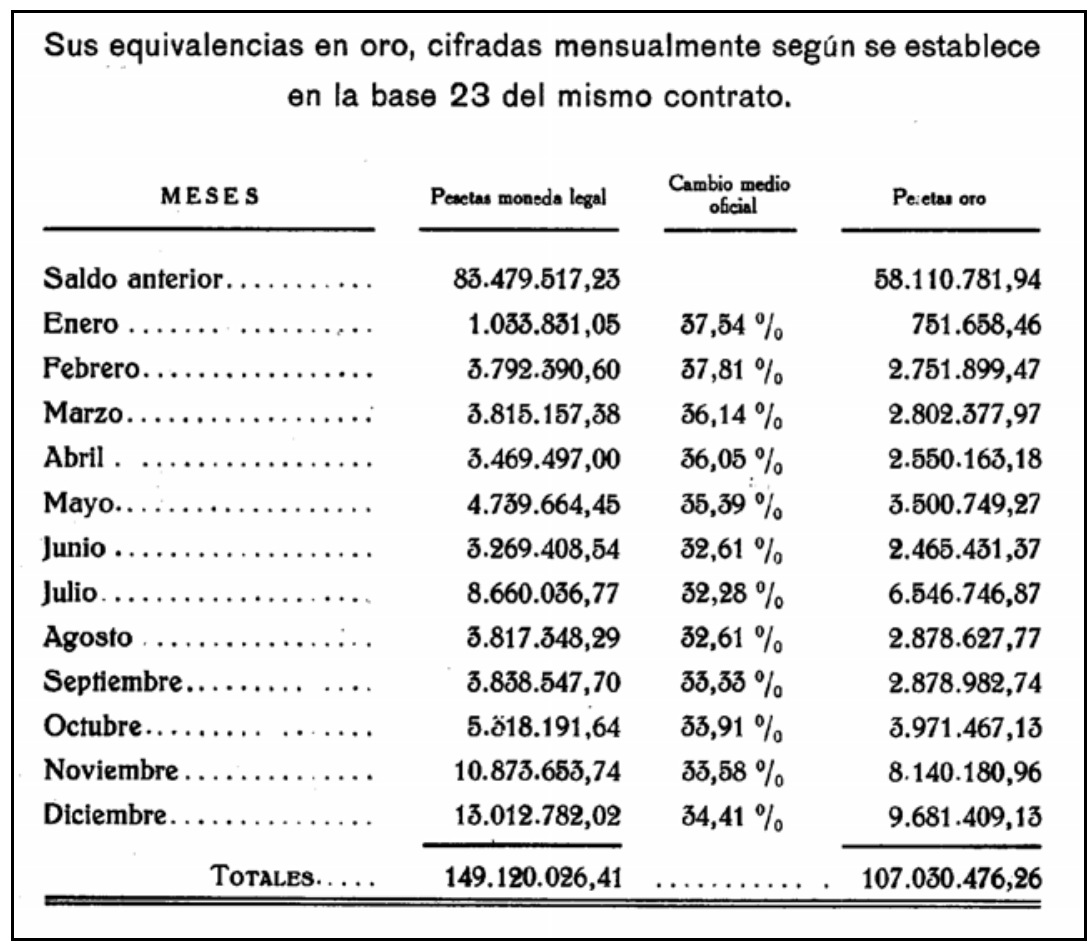

Fuente: Elaboración propia a partir de la Memoria CTNE 1925; pag.13

Aunque en la memoria no se indica explícitamente el cálculo, los distintos valores de la cantidad neta invertida en pesetas-oro mensuales se obtienen de la expresión [1]:

$$
\text { [1] } C N I_{p_{-} \text {oro }}=\frac{C N I_{p_{-} \text {cor }}}{\left(1+\frac{C M O_{m}}{100}\right)}
$$

Donde

$C N I_{p_{-} \text {oro }}=$ valor de la cantidad neta invertida en pesetas oro 
$C N I_{p_{-} \text {cor }}=$ valor de la cantidad neta invertida en pesetas corrientes

$C M O_{m}=$ valor porcentual del cambio medio oficial mensual

El valor anual de la cantidad neta invertida en pesetas oro y pesetas corrientes se obtiene al sumar los distintos valores mensuales al saldo correspondiente al ejercicio anterior. Cabe señalar que para el ejercicio 1925 no se detalla información sobre la valoración en pesetas corrientes ni su conversión en pesetas-oro correspondientes al ejercicio anterior 1924. Los valores mostrados por la empresa durante el periodo analizado se incluyen en la tabla 3.

$$
\text { --- insertar tabla } 3 \text { aquí --- }
$$

Cuanto mayor (menor) sea el valor del cambio medio oficial mensual, mayor (menor) será la depreciación de la peseta corriente con respecto a la peseta oro. A este respecto el tipo de cambio va disminuyendo gradualmente hasta el mes de abril de 1927, donde se observa el mínimo del periodo analizado en 8,40. A partir de esta fecha comienza un alza paulatina, alcanzando el máximo en diciembre de 1931 con 131,50.

Durante el periodo analizado únicamente se incluye en el ejercicio 1931 en la memoria un gráfico de barras mostrando la evolución del valor de la cantidad neta invertida en pesetas corrientes y en pesetas oro desde el inicio del Contrato en 1924 (véase figura 4).

Figura 4: Equivalencia mensual en pesetas-oro de la cantidad neta invertida

DE COMPUTIS Revista Española de Historia de la Contabilidad Spanish Journal of Accounting History 


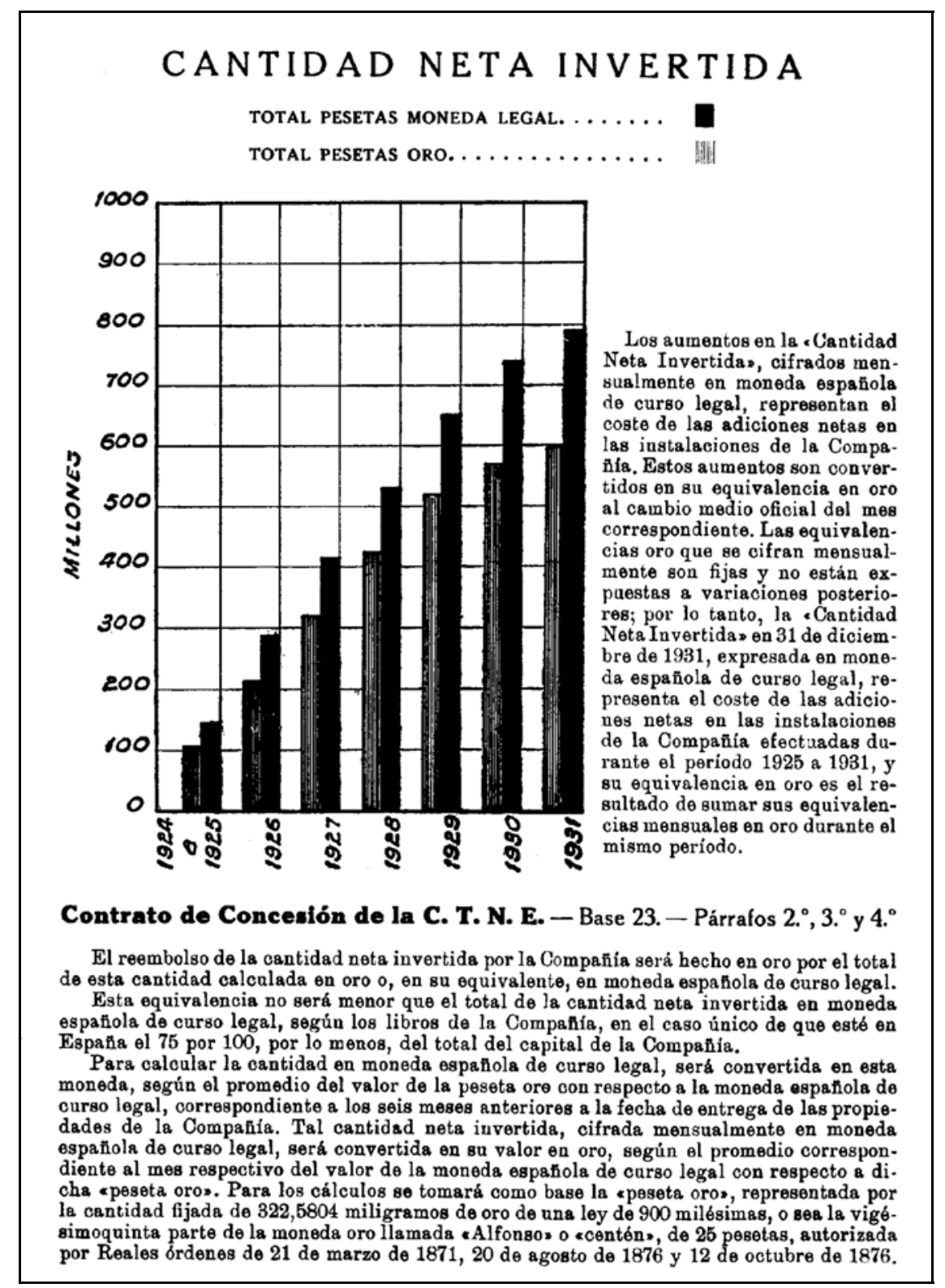

Fuente: Memoria CTNE 1931; pag.28

Además del gráfico de barras se incluye adicionalmente la redacción literal de la base vigésimo tercera donde se regula la conversión de la cantidad neta invertida en pesetas oro y una explicación del cálculo. 


\subsection{Críticas realizadas a la gestión de la $C T N E$ sobre la valoración de la Cantidad Neta Invertida.}

Durante los últimos tiempos de la Dictadura de Primo de Rivera surgieron con mayor fuerza críticas a la gestión de la compañía, subrayándose la pérdida de soberanía por el Estado ante una compañía "extranjera" a consecuencia de las condiciones pactadas en la concesión del monopolio en 1924. Algunas de estas críticas tuvieron mayor proyección social al realizarse en la tribuna de la Asamblea Nacional (Pérez-Yuste, 2004).

Una de ellas fue la interpelación pronunciada en 1928 por José Ayats Surribats a Primo de Rivera en Asamblea Nacional y que, tras la caída del Dictador, amplía en varias conferencias públicas en 1930 donde denuncia los abusos cometidos por la compañía con la aplicación de las bases del Contrato de concesión a la CTNE y el Reglamento de 21 de noviembre de 1929 (Pérez-Yuste, 2004).

Una de las conferencias, pronunciada en la Sociedad "La Única” en 1930 fue editada en 1931 con el título "Notas para el Estudio del problema telefónico en España” (Ayats, 1931), junto dos escritos. En uno, se comenta el Reglamento de 21 de noviembre de 1929, y en el otro, se hace un análisis de la posibilidad de incautación por el Estado del servicio telefónico.

En las voces críticas de este tiempo estaba presente la intención de incautar la CTNE y que el Estado fuera quien explotara el servicio telefónico. El principal obstáculo citado fue la necesidad de reembolsar la Cantidad Neta Invertida. En primer lugar, por la cantidad de dinero tan elevada que suponía para el Estado el rescate. Y en segundo lugar, que habría que esperar a la fecha de finalización de la concesión en 1944 o, en cualquier otra fecha, siempre y cuando la CTNE hubiese incumplido las condiciones del contrato.

Este estado de opinión crítico con la CTNE desembocó al poco tiempo de instaurase la Segunda República en España en un proceso legislativo en las Cortes Constituyentes conducente a la incautación del servicio prestado por la CTNE. Los trámites se iniciaron con el nombramiento de una Comisión que debía elaborar un dictamen que permitiera someter a las Cortes un Proyecto de Ley declarando ilegal la adjudicación, reforma y ampliación del servicio telefónico en 1924. La Comisión contó con un anteproyecto elaborado por el ministro de Comunicaciones, Martínez Barrios, presentándose a las Cortes finalmente el 10 de diciembre de 1931 como Proyecto de Ley (Pérez-Yuste, 2004).

En el preámbulo del Proyecto de Ley se realiza una exposición detallada de los diferentes incumplimientos atribuidos por el Estado a la CNTE a las distintas bases del Contrato que justifican la expropiación. En cuanto al reembolso de la cantidad neta invertida, el art. 3 del Proyecto de Ley indica que con posterioridad el Gobierno procedería a determinar una justa indemnización en garantía de los intereses legítimos afectados, por lo que no se tendría en cuenta la valoración realizada mediante la cantidad neta invertida a tal efecto.

Tras casi un año se inició a finales de noviembre de 1932 el estudio del Proyecto de Ley por la Comisión Parlamentaria de Gobernación, la cual designó una Ponencia que citó a declarar, a principios de diciembre, a Gumersindo Rico, secretario del consejo de administración de la CTNE, en calidad de representante de la compañía, el cual presentó un informe oral y unas alegaciones por escrito oponiéndose a los razonamientos incluidos del Proyecto de Ley que dan lugar a la expropiación. Toda la documentación relacionada con el Proyecto de Ley y las alegaciones efectuadas por la compañía se recogen en un libro publicado por la CTNE en 1933.

DE COMPUTIS Revista Española de Historia de la Contabilidad Spanish Journal of Accounting History 
Pocos días después de las alegaciones presentadas por la CTNE, el día 6 de diciembre de 1932, el presidente del gobierno, Manuel Azaña, realiza en el Congreso una proposición de "no ha lugar a deliberar" aprobada posteriormente por mayoría y que suspende la discusión en las Cortes de la expropiación de la CTNE.

No obstante, la intención del Gobierno de revertir al Estado los servicios telefónicos, o al menos de revisar las bases originales de la concesión persiste, ya que en 1933 se forma una Comisión con el fin de revisar las concesiones en materia de telecomunicaciones. Los trabajos de esta Comisión se recogen en un informe publicado por el Ministerio de Gobernación en 1933 (cit. en Pérez-Yuste, 2004).

En el mismo se indica, al igual que en el Proyecto de Ley, la imposibilidad de tomar la cantidad neta invertida contabilizada por la compañía como base justa de la valoración de la indemnización a satisfacer a la CNTE. En el informe se alude explícitamente que la complejidad del sistema contable de la CTNE, formado por un "sinnúmero de hojas auxiliares (...) que embarazan y entorpecen de un modo abrumador" (Gobernación, 1933; cit. PérezYuste, 2004, p.243), hace inviable un examen por parte de técnicos de Hacienda con el objeto de determinar un valor aproximado de la cantidad neta invertida.

Uno de los miembros de esta Comisión fue Agustín Muro Abad, Jefe de Sección de Teléfonos del Cuerpo de Telégrafos durante la Segunda República, quien publicó en la Revista Telégrafos durante 1932 una serie de artículos críticos con las condiciones de la concesión otorgada por el Estado a la CTNE, en donde se muestran datos de los métodos utilizados para manipular el valor de la cantidad neta invertida (Pérez Yuste, 2004)

Como se ha comentado anteriormente, las bases del Contrato dejan libertad a la compañía a la hora de valorar la cantidad neta invertida mediante su registro en los libros contables. Sobre la organización contable a seguir por la compañía, solamente se hace referencia en el Contrato en la base vigésimo cuarta, donde se dice lo siguiente: "Con respecto a la contabilidad general, la Compañía seguirá procedimientos establecidos por la práctica telefónica más adelantada."

En el Reglamento de 21 de noviembre no se amplía lo dispuesto en el Contrato sobre las prácticas contables a utilizar por la CTNE, haciendo únicamente alusión a que los procedimientos contables a utilizar deberán formar parte de los reglamentos “técnicos” (art. 30) y que éstos podrán aprobarse libremente por la compañía cuando lo juzgue oportuno, así como ampliarlos, modificarlos o derogarlos, teniendo la obligatoriedad únicamente la compañía de remitir a la delegación del Estado un ejemplar de los mismos (art. 34).

Por todo esto y teniendo además la ITT, en virtud del contrato privado firmado con la CTNE, la potestad de asesorar en cuestiones técnicas y organizativas, hace que la CTNE asuma desde el inicio de su actividad el modelo de contabilidad telefónica de la ITT (véase Acta $\mathrm{n}^{\circ} 7$ de la Reunión del Consejo de Administración de 26 de noviembre de 1924). Ese mismo día (véase Acta $\mathrm{n}^{0} 13$ de la Reunión del Comité Ejecutivo de la CTNE), el propio presidente de la ITT Sosthenes Behn explicó a los miembros del Comité Ejecutivo la forma en la que se llevaba la contabilidad telefónica en la ITT y en el resto de compañías asociadas. El comité consideró que este sistema era muy beneficioso y que se estudiaría su aplicación a la contabilidad de la CTNE (Blanco, 2011).

La responsabilidad en la adopción del modelo contable americano recayó, de igual forma que la mayoría de puestos de la alta dirección, en personal de la ITT. En un inicio, el norteamericano Geog .J. Strong fue el director del departamento "Intervención” y tenía entre otras responsabilidades la llevanza de la Contabilidad y la elaboración de las Cuentas. En un

DE COMPUTIS Revista Española de Historia de la Contabilidad Spanish Journal of Accounting History 
puesto subordinado a este departamento se encontraba el cargo de "Jefe de Contabilidad" ocupado por inicialmente por Luis Sousa.

Otro aspecto de interés relativo a la organización contable en los primeros años de actividad es la creación por la propia CTNE de una "Escuela de Contabilidad" en 1925 dentro de su programa de formación profesional para nuevos empleados y para aquellos que procedían de antiguas concesiones (Blanco, 2011).

Sin embargo, la imposición en la CTNE de un modelo contable norteamericano fue también objeto de críticas, como las señaladas por Ayats en la Asamblea Nacional en 1929, como cita Pérez Yuste (2004; pag.242-243):

\begin{abstract}
"Hay que tener en cuenta que la contabilidad de la ITT es un modelo (sic) y que han de ser normas norteamericanas las que han de tenerse en cuenta en esta contabilidad, $y$ muchos funcionarios españoles son simples autómatas, que no hacen más que poner los asientos que se les dice en los libros, pero que desconocen el valor de tales asientos, procurando, siempre que sea posible, que no conozcan el inglés algunos de ellos, por cuanto los jefes que dirigen esta Sección de Contabilidad, en inglés tramitan determinados asuntos, limitando el papel de los otros ser meramente unos escribientes.”
\end{abstract}

En términos generales, las críticas realizadas en cuanto a la valoración contable de la cantidad neta invertida coinciden en hacer hincapié en una notable inflación de las diferentes partidas contables de los activos que la componen, especialmente en las instalaciones, así como una insuficiente dotación de las amortizaciones de las mismas. Esta idea queda reflejada, de forma muy elocuente, en la siguiente reflexión que Ayats (1931, p.80-81) realiza sobre la utilidad de la información contable para determinar el importe a abonar en una posible incautación:

“ (...)[La CTNE] habrá de pretender que se les abonen tales bienes [incluidos en la Cantidad Neta Invertida] con arreglo al valor que les tiene asignado en sus cuentas, (...) Es claro que ésta [La CTNE] se ha cuidado en todo momento de hacer ver por todos los medios inimaginables que sus bienes tienen un valor considerablemente superior al que tienen en realidad. Y esto de ningún modo puede prevalecer, por muy en forma que aparezca acreditado en las cuentas de la Compañía, que, según todas las apariencias, son dignas de pasar a la Historia para ser colocadas en un plano superior a las famosas del Gran Capitán”.

Con respecto a la valoración contable de las instalaciones, construcciones y redes telefónicas son numerosas las críticas realizadas. Una de ellas es la relativa al alto precio pagado por la compañía en las adquisiciones de inmuebles y solares a particulares, en muchos casos mayores que los precios de mercado, para construir en las principales ciudades españolas edificios e instalaciones telefónicas.

Por ejemplo, Ayats (1931; p.13) cita el caso de un solar adquirido en Gijón por la CTNE que había sido vendido por el Ayuntamiento a un particular en pública subasta por 165.000 pesetas, y que éste se lo vendió a la CTNE por 525.000 pesetas unos diez días más tarde. También hace referencia a otros casos similares ocurridos en Oviedo, La Coruña, Vigo, León y Granada, dejando a entender que a la Compañía no le importa pagar un sobreprecio ya que formaría parte de la cantidad neta invertida.

DE COMPUTIS

No. 19

\section{Revista Española de Historia de la Contabilidad Spanish Journal of Accounting History}


La Compañía no es ajena a esta crítica como lo demuestra la información que proporciona a los accionistas en la memoria de 1928 a este respecto:

"Para atender al normal desarrollo de nuestra explotación, según lo requieren las necesidades de la misma, hemos adquirido en el pasado año algunos inmuebles. Al instalarnos no podemos hacerlo más que en sitios céntricos de las poblaciones por exigencias de la misma red y por las facilidades que evidentemente hemos de procurar al público; esto nos lleva a que no puedan regir las leyes corrientes de la oferta y la demanda, porque habiendo solamente demanda, la nuestra, tenemos que realizar los deseos de los vendedores bajo pena de desistimiento de instalación”

Fuente: Memoria Anual CTNE (1928; p.10-11)

Otra de las críticas señalada por Ayats (1931) y por Muro (1932; cit. En Pérez Yuste, 2004) es la diferente forma de valoración en las redes y centros telefónicos adquiridos al Estado con respecto a las que fueron adquiridas directamente por la CTNE a algunos concesionarios particulares.

Ayats (1931) critica la valoración de las redes y líneas telefónicas adquiridas al Estado por "lo onerosa que resultó al Estado y beneficiosa para la compañía” (pág.18). Aunque el precio pagado fue fijado por una comisión formada a tal efecto con representantes del Estado y de la CTNE, Ayats y Muro coinciden en señalar que el bajo valor final de la tasación fue consecuencia de que no se valoraran los derechos de reversión de las redes de líneas entonces en poder de concesionarios particulares ni los derechos de explotación en exclusiva del servicio telefónico. Además Muro indica que los coeficientes de depreciación utilizados hicieron disminuir notablemente el valor de las redes y líneas telefónicas.

Esta valoración contrasta con las adquiridas mediante negociación directa a los particulares. Según la base cuarta del Contrato, la compañía tiene libertad de convenir directamente con los concesionarios el precio, lo que provocó según se indica en la exposición de motivos del Proyecto de Ley de 1931 pagar un mayor importe por dichas adquisiciones del que si hubiera sido establecido por el Estado.

Otra de las posibles causas del alto precio pagado en algunos casos es señalada por Muro (1932; cit. En Perez Yuste, 2004) al indicar que la valoración de las redes e instalaciones se realizó considerando los concesionarios como propietarios de las mismas y no como usufructuarios, incumpliendo por lo tanto la base cuarta del Contrato. Por otra parte, también Ayats (1931) critica que la CTNE no hubiera esperado al término de algunas concesiones que al revertirse en breve plazo de tiempo al Estado, hubieran pasado de forma gratuita a la Compañía.

Sin embargo, la principal fuente de críticas hace referencia a la valoración de las construcciones, instalaciones y redes llevadas a cabo por la propia Compañía. La base decimoquinta del Contrato detalla un amplio programa de construcción, ampliación y modernización de instalaciones por todo el territorio nacional a realizar por la CTNE durante la concesión. No obstante, las críticas señalan que aunque se desarrollaba el programa convenido, también se realizaban "con gran profusión construcciones no concertadas, costosísimas y de muy discutible necesidad y conveniencia” (Muro, 1932; p.4 cit. En Perez-Yuste, 2004). Según

DE COMPUTIS Revista Española de Historia de la Contabilidad Spanish Journal of Accounting History 
Ayats (1931, p.24) la explicación del gran esfuerzo inversor realizado por la Compañía radicaba en que éste era el verdadero negocio de la CTNE:

“La Compañía no pierde de vista la base $23^{a}$ del contrato de concesión; le interesa inflar las cantidades de las construcciones ante la perspectiva de que en fin de cuentas todo lo pagará el Estado. A los extranjeros dueños del monopolio no les interesa, repito, la explotación del servicio telefónico, lo único que les interesa son las construcciones".

Ayats (1931) concluye a través de una comparativa de los costes imputados en la valoración de instalaciones telefónicas, como el colgado de líneas urbanas e interurbanas o la plantación de postes telefónicos, que la CTNE tiene sobrevalorado el valor de las construcciones en un cincuenta y nueve por ciento con respecto a la red urbana y provincial de San Sebastián.

Ayats (1931) atribuye un mayor coste a varias causas. Por un lado, debido a que la adquisición de materiales se realiza sin subastas ni concursos públicos, a través de la propia ITT o de alguna de sus filiales en España como la Standard Eléctrica, alcanzado precios muy superiores. Además muchos de los materiales son importados directamente de Estados Unidos en vez de adquiridos a empresas españolas, o son adquiridos inicialmente por la ITT o la Standard Eléctrica a empresas españolas para luego ser revendidos a la CTNE.

Por otro lado, Muro (1932; cit en Pérez-Yuste, 2004) y Gobernación (1933; cit en Perez-Yuste, 2004) coinciden con Ayats (1931) en señalar que se son cuantiosos los cargos imputados a las construcciones relacionados con comisiones efectuadas por la ITT por asesoramiento técnico y por compras de materiales, así como unos intereses intercalarios calculados por la propia empresa.

Por último, son unánimes también las críticas por el escaso valor de la depreciación reconocida y que viene a disminuir el valor de la cantidad neta invertida. En contra del criterio de la Delegación del Gobierno, el Reglamento vino a aprobar en 1929 unos porcentajes mínimos de depreciación para el periodo de explotación, que son considerados insuficientes.

A este respecto señala por ejemplo Ayats (1931) que con los porcentajes aprobados, y teniendo las instalaciones una vida media de quince a veinte años, solamente se podrán depreciar en los quince años que quedan de la concesión menos de un 30\% de su valor inicial, cuando la amortización debería ser del orden del 85 al 90\%. Para alcanzar este valor según el Proyecto de Ley de 1931 deberían de pasar al menos treinta y cinco años de explotación.

Un aspecto adicional que podría justificar aún más la insuficiente depreciación reconocida por la CTNE y que no ha sido señalada por los contemporáneos ni por la literatura académica es comparar las políticas de reconocimiento de la depreciación con las llevadas a cabo por otras empresas telefónicas o por la propia ITT. Son escasos los trabajos académicos en Historia de la Contabilidad que han explorado las prácticas contables sobre depreciación de activos en empresas telefónicas. Un ejemplo reciente lo constituye la realizada por Collier (2012) sobre la adopción de métodos de depreciación distintos al lineal por el grupo de empresas americano Bell System a inicios del siglo XX.

Al respecto de la ITT, ésta reconoce expresamente en la nota 12 a los estados contables del informe anual de 1935 que la depreciación de instalaciones y redes adoptadas por algunas

DE COMPUTIS

\section{Revista Española de Historia de la Contabilidad Spanish Journal of Accounting History}


compañías subsidiarias, como la CTNE, es sustancialmente menor que las reconocidas para otras empresas telefónicas subsidiarias del grupo. La razón ofrecida por la ITT es que se limita a cumplir en el caso de la CTNE con al porcentaje acordado en el contrato. En 1935 este valor alcanza el 1,750\%, para la CTNE, mientras que con carácter general el porcentaje aplicado en otras subsidiarias del grupo es de al menos el $4 \%$.

Según Blanco (2011), la lectura de las Actas del Consejo de Administración hasta 1925 indica que los Delegados del Gobierno fueron demasiado condescendientes, limitándose a aprobar como el resto de consejeros las acciones propuestas por la Compañía. La única petición que efectúa uno de los Delegados en este periodo, es un mayor desglose en el informe de los gastos de explotación a presentar al Consejo de Administración mensualmente, cuestión que al parecer no fue atendida por la compañía.

Esta actitud de escaso rigor en la fiscalización de las acciones de la Compañía de los Delegados del Gobierno parece que pudo llevar a su destitución en 1928 por Primo de Rivera. Según el Proyecto de Ley (1931) la nueva Delegación del Gobierno en 1929 denegó la aprobación de las cuentas de 1928. La Compañía tuvo que corregir de la cantidad neta invertida varios importes, principalmente los derivados del impuesto del timbre que estaban incluidos en los gastos amortizables.

En resumen, la inversión en nuevas construcciones y renovaciones había elevado de forma importante la cantidad neta invertida, al aumentar el coste de las redes e instalaciones y al considerar una escasa depreciación de estos activos. El Proyecto de Ley (1931) señalaba además que en algunos casos no eran factibles ni económica ni técnicamente. Esta situación perjudicaba tanto a los usuarios, por las mayores tarifas que debían pagar, como al Estado por el mayor importe a satisfacer en el momento de la reversión.

\section{Conclusiones}

El trabajo ha pretendido explorar, desde una perspectiva histórico contable, una herramienta clave, y como se ha visto también problemática, como fue la cantidad neta invertida por la CTNE y mediante la cual se valoraba la inversión directa extranjera realizada por la empresa americana ITT.

El análisis llevado a cabo en el trabajo ha permitido identificar las prácticas de divulgación sobre la cantidad neta invertida llevadas a cabo por la CTNE en la memoria anual en relación con lo dispuesto en las Bases del Contrato y su Reglamento. A este respecto la empresa incluye en la memoria anual, en primer lugar, un estado donde se muestra su composición, distinguiendo la inversión bruta de la depreciación acumulada. En segundo lugar, se incluye un estado de conversión mensual de las inversiones realizadas en el ejercicio en pesetas oro, el cual tiene como objeto asegurar la inversión realizada durante el periodo concesional ante una depreciación de la peseta en el momento del rescate por el Estado. En tercer lugar, un informe elaborado por la Delegación del Gobierno donde se aprueban las cuentas presentadas y la valoración realizada de la cantidad neta invertida en el ejercicio.

Asimismo, en el trabajo se han expuesto las principales críticas realizadas en su tiempo en cuanto a la valoración contable de esta partida. De las críticas realizadas a la compañía, resaltan la insuficiente depreciación contable de las infraestructuras telefónicas, la consideración como gasto amortizable el impuesto del Timbre y el elevado valor de adquisición de ciertas construcciones a tenor de los diferentes costes imputados a las mismas.

DE COMPUTIS Revista Española de Historia de la Contabilidad Spanish Journal of Accounting History 
Tabla 1: Composición de la Cantidad Neta Invertida (1925-1932)

$$
1925
$$

1926

1927

1928

Propiedades y derechos de la Compañía

Depósitos en Garantía

Valores en Suspenso

Materiales de almacen

Gastos amortizables

A deducir:Saldo de la cuenta "Fondos de Reserva"

A deducir: Por "Reservas y Amortizaciones"

Cantidad Neta Invertida (ptas)
$123.920 .455,08$

$556.274,85$

$14.096 .741,40$

$10.715 .870,92$

$242.047 .542,87$

$327.799,82$

$30.655 .390,74$

22.048.951,91

Total

$149.289 .342,25$

$169.315,84$

$295.079 .685,34$
$377.916 .569,32$

$375.736,75$

$20.615 .667,09 \quad 20.293 .403,86$

$26.047 .816,71 \quad 31.930 .873,90$

424.955.789,87 541.106.317,72

4.295.474,31

$8.406 .652,85$

149.120.026,41 290.784.211,03

416.549.137,02

$488.882 .039,96$

$12.531 .319,83$

528.574.997,89

\section{9}

1930

1931

1932

Propiedades y derechos de la Compañía

$613.842 .013,50$

$707.236 .697,29$

$774.456 .472,33$

$828.452 .219,06$

Depósitos en Garantía

Valores en Suspenso

Materiales de almacen

$17.962 .314,07$

$17.417 .380,92$

14.943.620,33

$9.330 .729,78$

Gastos amortizables

A deducir:Saldo de la cuenta "Fondos de Reserva"

A deducir: Por "Reservas y Amortizaciones"

$18.074 .740,54$

$27.902 .969,73$

38.979.090,21

$50.861 .366,10$

Cantidad Neta Invertida (ptas)

655.215.279,37 738.408.032,28

792.151.426,25

828.701.262,04

Nota: Datos en pesetas corrientes. Fuente: Elaboración propia a partir de las Memorias Anuales de 1925-1931. 


\begin{tabular}{|c|c|c|c|c|c|c|c|}
\hline \multicolumn{8}{|c|}{ Tabla 2 - Reservas y Amortizaciones (1926-1932) } \\
\hline & 1926 & 1927 & 1928 & 1929 & 1930 & 1931 & 1932 \\
\hline $\begin{array}{l}\text { [1] Propiedades y derechos de la } \\
\text { Compañía }\end{array}$ & $242.047 .542,87$ & $377.916 .569,32$ & $488.882 .039,96$ & $613.842 .013,50$ & $707.236 .697,29$ & $774.456 .472,33$ & $828.452 .219,06$ \\
\hline [2] Materiales de almacen & $30.655 .390,74$ & $20.615 .667,09$ & $20.293 .403,86$ & $17.962 .314,07$ & $17.417 .380,92$ & $14.943 .620,33$ & $9.330 .729,78$ \\
\hline [3] Gastos amortizables & 22.048.951,91 & $26.047 .816,71$ & $31.930 .873,90$ & $41.485 .692,34$ & $41.656 .923,80$ & $41.730 .423,80$ & $41.779 .679,30$ \\
\hline [4] Reservas y Amortizaciones & $4.295 .474,31$ & $8.406 .652,85$ & $12.531 .319,83$ & $18.074 .740,54$ & $27.902 .969,73$ & $38.979 .090,21$ & $50.861 .366,10$ \\
\hline $\begin{array}{l}\text { s/ propiedades e instalaciones, } \\
\text { materiales de almacén y gastos } \\
\text { amortizables (\%) }\end{array}$ & $1,46 \%$ & $1,98 \%$ & $2,32 \%$ & $2,68 \%$ & $3,64 \%$ & $4,69 \%$ & $5,78 \%$ \\
\hline $\begin{array}{l}\text { [5] Dotación Anual "Reservas y } \\
\text { Amortizaciones" }\end{array}$ & $4.126 .158,47$ & $4.111 .178,54$ & 4.124.666,98 & $5.543 .420,71$ & $9.828 .229,19$ & $11.076 .120,48$ & $11.882 .275,89$ \\
\hline $\begin{array}{l}\text { Aumento sobre la Cantidad Neta } \\
\text { Invertida del año anterior (\%) }\end{array}$ & & $1,41 \%$ & $0,99 \%$ & $1,05 \%$ & $1,50 \%$ & $1,50 \%$ & $1,50 \%$ \\
\hline $\begin{array}{l}\text { [6] Depreciacion anual de redes e } \\
\text { instalaciones }\end{array}$ & $850.000,00$ & $1.500 .000,00$ & $1.800 .000,00$ & $3.300 .000,00$ & $6.266 .313,64$ & $7.196 .463,02$ & $7.706 .168,88$ \\
\hline $\begin{array}{l}\text { s/ dotación anual "Reservas y } \\
\text { Amortizaciones" (\%) }\end{array}$ & $20,60 \%$ & $36,49 \%$ & $43,64 \%$ & $59,53 \%$ & $63,76 \%$ & $64,97 \%$ & $64,85 \%$ \\
\hline $\begin{array}{l}\text { [7] Amortizacion anual de gastos } \\
\text { amortizables }\end{array}$ & $150.000,00$ & $500.000,00$ & $600.000,00$ & $825.000,00$ & $1.140 .000,00$ & $1.560 .000,00$ & $2.160 .000,00$ \\
\hline $\begin{array}{l}\text { s/ dotación anual "Reservas y } \\
\text { Amortizaciones" (\%) }\end{array}$ & $3,64 \%$ & $12,16 \%$ & $14,55 \%$ & $14,88 \%$ & $11,60 \%$ & $14,08 \%$ & $18,18 \%$ \\
\hline
\end{tabular}

Nota: Datos en pesetas corrientes. Para evitar inconsistencias en los cálculos se muestran los datos sobre dotaciones a reservas y amortizaciones a partir de 1926. Por la misma razón el aumento de la cantidad neta invertida se muestra a partir de 1927. Fuente: Elaboración propia, datos obtenidos de las Memorias Anuales de 1926-1932

\section{DE COMPUTIS}

No. 19

\section{Revista Española de Historia de la Contabilidad}

Spanish Journal of Accounting History 
Tabla 3: Equivalencia oro de la CNI (1925-1932)

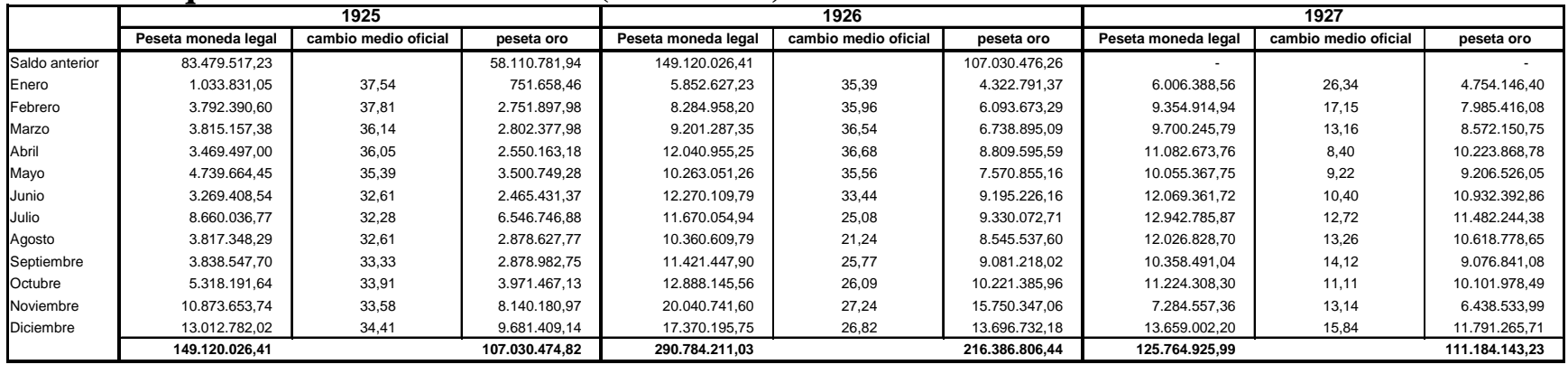

\begin{tabular}{|c|c|c|c|c|c|c|c|c|c|}
\hline & \multicolumn{3}{|c|}{1928} & \multicolumn{3}{|c|}{1929} & \multicolumn{3}{|c|}{1930} \\
\hline & Peseta moneda legal & cambio medio oficial & $\begin{array}{l}\text { peseta oro } \\
\end{array}$ & Peseta moneda legal & cambio medio oficial & peseta oro & Peseta moneda legal & cambio medio oficial & peseta oro \\
\hline Saldo anterior & $416.549 .137,02$ & & $327.570 .949,50$ & $528.574 .997,89$ & & $423.966 .296,07$ & $655.215 .279,37$ & & $520.672 .172,81$ \\
\hline Enero & $6.937 .311,02$ & 13,83 & $6.094 .448,76$ & $6.892 .463,25$ & 17,93 & $5.844 .537,65$ & $2.605 .513,03$ & & $1.793 .565,79$ \\
\hline Febrero & $9.389 .597,62$ & 13,60 & $8.265 .490,86$ & $6.706 .133,98$ & 20,89 & $5.547 .302,49$ & $5.395 .918,29$ & 46,31 & 3.688.003,75 \\
\hline Marzo & $11.860 .633,06$ & 14,71 & $10.339 .667,91$ & $11.069 .868,05$ & 26,80 & $8.730 .179,85$ & $6.475 .657,73$ & 51,64 & $4.270 .415,28$ \\
\hline Abril & $8.422 .181,36$ & 15,10 & $7.317 .273,12$ & 22.964.573,73 & 28,18 & 17.915.879,02 & $5.500 .543,41$ & 56,51 & 3.514.499,65 \\
\hline Mayo & $12.018 .680,05$ & 15,69 & 10.388.693,97 & $9.906 .929,64$ & 34,10 & $7.387 .717,85$ & 7.586.245, & 54,49 & $4.910 .509,27$ \\
\hline Junio & $9.110 .118,11$ & 15,96 & $7.856 .259,15$ & $8.823 .900,11$ & 36,07 & $6.484 .824,07$ & 8.642.250,38 & 56,80 & $5.511 .639,27$ \\
\hline Julio & $8.546 .617,07$ & 16,89 & $7.311 .675,14$ & 15.129.011,77 & 34,03 & $11.287 .780,18$ & 7.915.593,62 & 62,88 & $4.859 .770,15$ \\
\hline Agosto & $\begin{array}{l}8.044 .896,57 \\
7\end{array}$ & 16,27 & $6.919 .150,74$ & $\begin{array}{l}7.658 .286,05 \\
.00009\end{array}$ & 31,62 & $5.818 .482,03$ & 6.563.091, 62 & 67,15 & $\begin{array}{l}3.926 .468,21 \\
5\end{array}$ \\
\hline Septiembre & 7.701.892,90 & 15,94 & 6.642.998,88 & 10.604.908,47 & 30,52 & 8.125.121,41 & $\begin{array}{l}9.042 .257,25 \\
.70 .25\end{array}$ & 78,20 & $5.074 .218,43$ \\
\hline Octubre & $\begin{array}{l}7.719 .008,58 \\
\end{array}$ & 17,70 & $\begin{array}{l}6.558 .206,10 \\
7.052501727\end{array}$ & $\begin{array}{l}3.143 .514,25 \\
0.523010\end{array}$ & 31,35 & $\begin{array}{l}2.393 .235,06 \\
\end{array}$ & $\begin{array}{l}7.122 .592,53 \\
\end{array}$ & 79,57 & 3.966.471,31 \\
\hline Noviembre & $\begin{array}{r}9.9882 .5652 .52 \\
12.792 .362 .01\end{array}$ & $\begin{array}{l}1,924 \\
19,01\end{array}$ & $\begin{array}{r}\begin{array}{r}.955 .25051,27 \\
10.748 .980,77\end{array} \\
\end{array}$ & $\begin{array}{l}9.533 .30001,199 \\
14.207 .690,69\end{array}$ & $\begin{array}{l}3,690 \\
39,33\end{array}$ & $\begin{array}{r}6.673 .666,65 \\
10.197 .151 .14\end{array}$ & $\begin{array}{r}6.3225 .522,15 \\
10.017 .267,13\end{array}$ & $\begin{array}{l}88,61 \\
75,52\end{array}$ & $\begin{array}{l}3.353 .916,6,63 \\
5.707 .194,13\end{array}$ \\
\hline & $528.574 .997,89$ & & $423.966 .296,17$ & $655.215 .279,37$ & & $520.672 .172,88$ & $738.408 .032,28$ & & $571.248 .844,69$ \\
\hline
\end{tabular}

\begin{tabular}{|c|c|c|c|c|c|c|}
\hline & \multicolumn{3}{|c|}{1931} & \multicolumn{3}{|c|}{1932} \\
\hline & Peseta moneda legal & cambio medio oficial & peseta oro & Peseta moneda legal & cambio medio oficial & \\
\hline Saldo anterior & $738.408 .032,28$ & & $571.248 .844,65$ & $792.151 .726,25$ & & $598.057 .260,31$ \\
\hline Enero & 2.102.851,86 & 83,86 & $1.143 .724,50$ & 2.044.369,76 & 128,83 & $893.401,11$ \\
\hline Febrero & 6.331.564,65 & 90,00 & 3.332.402,45 & 3.692.900,96 & 142,49 & $1.522 .908,56$ \\
\hline Marzo & $5.145 .556,55$ & 82,17 & 2.824.590,52 & 2.261.951,39 & 152,44 & $896.035,25$ \\
\hline Abril & 5.544.676,31 & 80,04 & $3.079 .691,35$ & $360.995,97$ & 154,81 & $141.672,61$ \\
\hline & 5.373.755,87 & 88,56 & 2.849.891,74 & 4.201.149,18 & 144,68 & $1.716 .997,38$ \\
\hline & 5.536.294,70 & 100,08 & 2.767.040,53 & 5.446.639,71 & 135,13 & $2.316 .437,59$ \\
\hline Julio & 3.596.003,46 & 101,52 & 1.784.439,99 & 2.033.899,96 & 136,57 & $859.745,51$ \\
\hline Agosto & 3.223.845,85 & 116,91 & 1.486.259,67 & 5.409.865,339 & 139,24 & 2.261.271,27 \\
\hline Septiembre & $2.579 .884,46$ & 114,89 & $1.200 .560,50$ & $2.095 .699,17$ & 139,55 & $874.848,33$ \\
\hline Octubre & $2.347 .243,33$ & 115,84 & 1.087.492,28 & 1.424.506,04 & 135,94 & $603.757,75$ \\
\hline Noviembre & $4.075 .542,32$ & 120,82 & $1.845 .640,03$ & 1.571.946,02 & 135,63 & $667.124,74$ \\
\hline Diciembre & 7.886.474,61 & 131,50 & $\begin{array}{l}3.406 .684,50 \\
\end{array}$ & $6.005 .612,24$ & 136,64 & $2.537 .868,59$ \\
\hline & 792.151.726,25 & & 598.057.262,71 & 828.701.262,04 & & 613.349.329,00 \\
\hline
\end{tabular}

Fuente: Elaboración propia, datos obtenidos de las Memorias Anuales de 1925-1932.

\section{DE COMPUTIS}

Revista Española de Historia de la Contabilidad Spanish Journal of Accounting History

No. 19 


\section{Referencias bibliográficas}

Ayats, J. (1931): “Notas para el estudio del problema telefónico en España”, Madrid, Imprenta Samarán y Cía.

Blanco, L. (2011): “La creación de la Compañía Telefónica Nacional de España vista a través de su Consejo de Administración”. Trabajo Fin de Máster. Universidad Politécnica de Madrid.

Cabezas, J. A. (1974): “Cien años de teléfono en España. Crónica de un proceso técnico”, Madrid, Espasa Calpe.

Calvo, A. (1998): “El teléfono en España antes de Telefónica (1877-1924)”.Revista de historia industrial, vol.13, p.59-81.

-- (2006). Telefónica toma el mando. Monopolio privado, modernización y expansión de la telefonía en España, 1924-1945. Revista de Historia Industrial, (32), 69-98.

-- (2010): “Historia de Telefónica: 1924-1975”.Fundación Telefónica, Madrid.

Campillo, M. (1963): “Las inversiones extranjeras en España (1850-1950) Gráficas Manfer. Madrid

Carballo, R. (1979), “El capital extranjero y la dictadura. La ITT en España”, Cuadernos Económicos de I.C.E., 10, pp. 579-600.

Compañía Telefónica Nacional de España (CTNE). Memorias Anuales entre 1924 y 1932. Madrid.

-- (1930): “Estatutos, Contrato de Concesión, Reglamento y Legislación”. Rafael Caro Raggio, Impresor. Madrid.

-- (1933): “La Compañía Telefónica Nacional de España: Situación de derecho en virtud de su contrato con el Estado: Situación de hecho por la obra realizada”. Edición facsímil de 1988 de la edición original de 1933, editada en Madrid por J. Sánchez de Ocaña.

Collier, D. (2012): “A contextual analysis of the development and diffusion of depreciation accounting at the Bell System, 1910-37”, Accounting History Review, 22:1, p.23-45

Gobernación (1933 cit. en Pérez Yuste, 2004): “Informe emitido por la Comisión de Revisión de Concesiones de Servicios de Telecomunicación”. Subsecretaría de Comunicaciones del Ministerio de la Gobernación. Diana Artes Gráficas. Madrid. 1933.

Hernández Esteve, E. (2013): “Aproximación al estudio del pensamiento contable español”. AECA. Madrid.

Herranz, A. (2004): “La dotación de infraestructuras en España: 1845-1935”. Banco de España Servicio de Estudios.

International Telephone and Telegraph Corporation (ITT): “Annual Report 1935”, Nueva York.

Little, D. J. (1979): “Twenty years of turmoil: ITT, the State Department, and Spain, 1924-1944”. The Business History Review, p.449-472.

Martínez Ovejero, A. M. (2004): “Azaña versus Telefónica: los límites del poder. Espacio, tiempo y forma”. Serie V, Historia contemporánea, (16), p.121-148.

Muro (1932; cit Pérez Yuste, A. (2004): “Estudio del contrato celebrado entre el Estado y la Compañía Telefónica Nacional de España”, Colección de artículos publicados en la revista Telégrafos en 1932.

Nadal, J. (2007). "El nacimiento del teléfono en España. Las dificultades del crecimiento de un nuevo sistema de comunicaciones, 1880-1924”. Cuadernos de Historia Contemporánea, 29, p.35-56.

Pérez Yuste, A. (2004): “La Compañía Telefónica Nacional de España en la dictadura de Primo de Rivera”, tesis doctoral inédita, Universidad Politécnica de Madrid.

Real Decreto de 25 de agosto de 1924 en el que se incluyen las Bases del contrato entre el Estado Español y la CTNE.

Real Decreto de 21 de noviembre de 1929 en el que se aprobó el Reglamento para la ejecución del contrato celebrado entre el Estado y la CTNE.

Tortella, G. (2008): “El capital extranjero en la formación del capitalismo español” en Tascón Fernández, J. (Eds) La inversión extranjera en España, Madrid. Editorial Minerva. p. 31-47.

DE COMPUTIS Revista Española de Historia de la Contabilidad Spanish Journal of Accounting History 
María Araceli Casasola Balsells es profesora colaboradora del Departamento de Economía Financiera y Contabilidad de la Universidad Pablo de Olavide. Su e-mail es: macasbal@upo.es

Vicente A. Pérez Chamorro es profesor colaborador del Departamento de Economía Financiera y Contabilidad de la Universidad Pablo de Olavide. Su e-mail es: vapercha@upo.es

Mariano Sánchez Barrios es profesor titular del Departamento de Contabilidad y Economía Financiera de la Universidad de Sevilla. Su email es: msanchez@us.es

Fernando Gutiérrez Hidalgo es catedrático de Contabilidad y Economía Financiera de la Universidad Pablo de Olavide de Sevilla, Sevilla. Su e-mail es: fguthid@upo.es

María Araceli Casasola Balsells is lecturer at the Department of Finance and Accounting at the University Pablo de Olavide. Her e-mail is: macasbal@upo.es

Vicente A. Pérez Chamorro is lecturer at the Department of Finance and Accounting at the University Pablo de Olavide. His e-mail is: vapercha@upo.es

Mariano Sánchez Barrios is Assistant Professor of Accounting and Finance at the University of Seville. His email is: msanchez@us.es

Fernando Gutiérrez Hidalgo is Professor of Accounting and Finance at the Universidad Pablo de Olavide de Sevilla, Seville, Spain. His e-mail is: fguthid@upo.es 